\title{
8
}

\section{Computer-aided school management in North-Rhine Westphalia: The Kaufmaennische Schulen (College of Commerce) in Ahaus}

\author{
Gregor Kuhlmann \\ Kaufmaennische Schulen, Kusenhook 4 - 8, D 48683 Ahaus, Germany
}

\begin{abstract}
In the Federal Republic of Germany there is no uniform concept for computer-aided school administration. The authorities involved in administering schools as well as the schools themselves employ programs specially suited to their various demands. These programs employed in the schools must allow decentralized gathering of data. In order to minimize effort involved in changing the programs, the important conditions for writing reports are to be formalized in decision tables which can be evaluated by the program. In order to enable data communication between the parties involved, new developments should only take place on the basis of SQLdatabase systems.
\end{abstract}

Keyword Codes: B.4.m, K.3.0

Keywords: Input/Output and Data communications, Miscellaneous; Computing Milieux, Computers and Education, General

\section{FRAMEWORK FOR SCHOOL MANAGEMENT: THE GERMAN SCHOOL SYSTEM}

A systematic concept for computer-aided school management is not to be found in Germany. This is quite surprising, considering that the state of North-Rhine Westphalia alone employs 163,000 teachers in over 10,000 schools. About $22 \%$ of the population of Germany lives in this state. School expenses play an important role in the budget of the 16 federal states.

The reason for the small degree of integration of computer systems in school administration lies in the structure of the German school system. There exists in the Federal Republic of Germany a separative school system, as can be seen in figure 1 .

The school system in Germany is not centrally controlled. Each state has its own educational laws. The federal Ministers of Education jointly agree on their educational policies. They fix a framework for the curriculum for the individual subjects in the various school levels. Representatives from industry and the trade unions are also involved in the development of the curriculum of vocational schools. Within this national framework each state develops its own refined curricula. And in the schools themselves an internal curriculum is put into practice on the basis of the respective state's curriculum. 
Employment

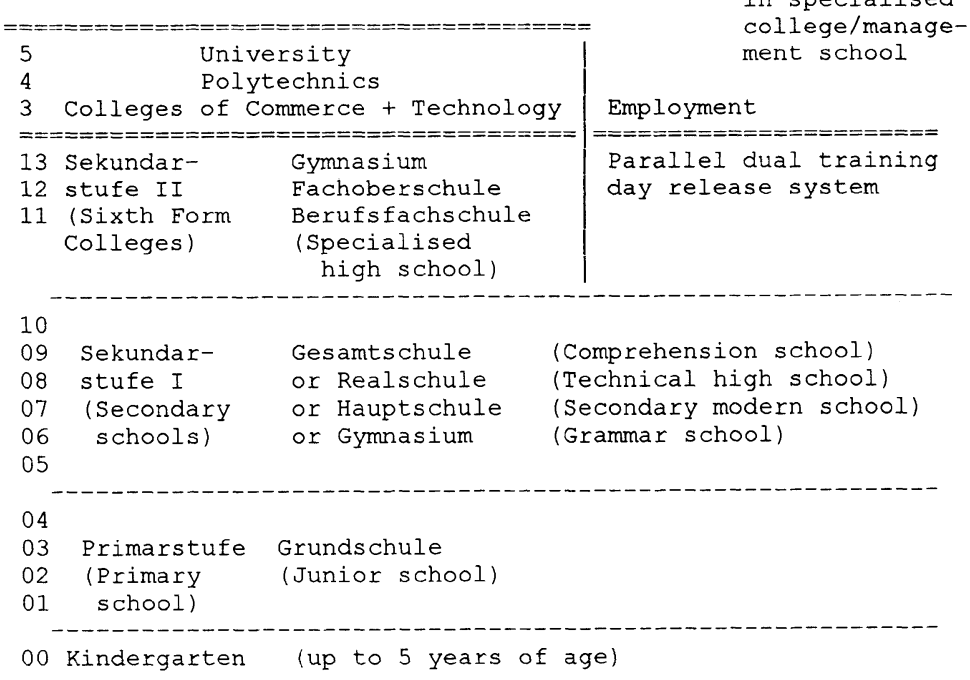

Figure 1. The German school system

Each state employs teachers corresponding to the estimated requirements. With very few exceptions all teachers must have completed a degree course at the university (M.A. or M.Sc.). The length of study varies: A student aiming for a position as a teacher at a primary school can complete his course of studies in about three years. Qualification of a teacher at a grammar school or college of higher education usually takes more than four years. The state is responsible for the practical training in the schools. This practical training lasts two years and is completed by a state exam. Teacher training is based on the relevant school subjects, and also includes pedagogy, philosophy, sociology and psychology. There is no systematic training in problems of school management at any phase of teacher training.

Exactly what kinds of schools are available in any region or city is a matter for the local authorities. In agreement with the Minister of Education or the subordinate authorities they must ensure that the basic educational requirements are met in all cases. As local level education is a very important political matter, politicians ensure that the young citizens are offered a wide choice of schools.

On the basis of these facts one can see that the German educational landscape is very varied. This impression is reinforced in the individual schools. The degree of variation within the schools is best seen in the example of colleges of higher education. It is hard to find even two that are structured in the same way. 


\section{BASIC FRAMEWORK FOR THE INTERNAL ORGANIZATION OF A SCHOOL}

The head of the school, who is always a teacher, is the legal representative of the school and responsible for the organizational and pedagogical running of the school. He is supported by a deputy head. In the case of colleges of higher education, which are mostly divided into departments, the departmental heads take over some of the administrative tasks.

This committee determines in agreement with the local authorities (LEA) exactly how the internal administration is organized. Local authorities are responsible for fitting out the schools (buildings, rooms, computers, office personnel). As these authorities employ as little administrative personnel as possible for economical reasons, many of the administrative tasks must be executed by the teachers themselves. Computers are well suited for carrying out such work. Many local authorities are, however, not really interested in minimizing the teacher's administrative burden. On the one hand, buying computers and the required programs puts a strain on their budget, and on the other, the teacher's working time is a state matter. And the state for its part sees no reason to get involved in the administrative affairs of the local authorities.

The state of North-Rhine Westphalia is interested in equipping school administration with computers. Because it cannot force the local authorities to do this, it now plans to equip each school with a PC in the next few months. They are however not doing this with the aim of reducing the teacher's workload. The ministry's motive is that it would like to acquire up-todate personnel planning data by means of a data communication system. In order to achieve this the schools have to supply data regarding numbers of pupils and employment of teachers four times a year. In order to motivate schools to undertake this statistical work, the Minister of Education supplies all interested schools with a time table production program as well as a student data administration program which run under the operating system MS-WINDOWS 3.1 in the single mode.

\section{SCHEMES REALIZED FOR COMPUTER-AIDED SCHOOL MANAGEMENT}

A large part of the administrative programs applied in colleges of higher education are the teacher's own initiative. The achievement spectrum ranges from monofunctional programs in DBASE to integrated program systems on UNIX-systems. The integrated program systems normally include the following functions:

- administration of student data

- writing of reports

- time-table production program

- production of the substitution plans

- lending of school books

- inventory administration

- statistics

\subsection{Organizational requirements of a school administration application}

The organizational requirements that must be met by school administration software can be illustrated by the following two aspects. 


\section{Fluctuating workload}

In school administration the tasks occurring are not spread uniformly over the course of a school year. As can be seen in the figure 2 there are several peak work periods within the year.

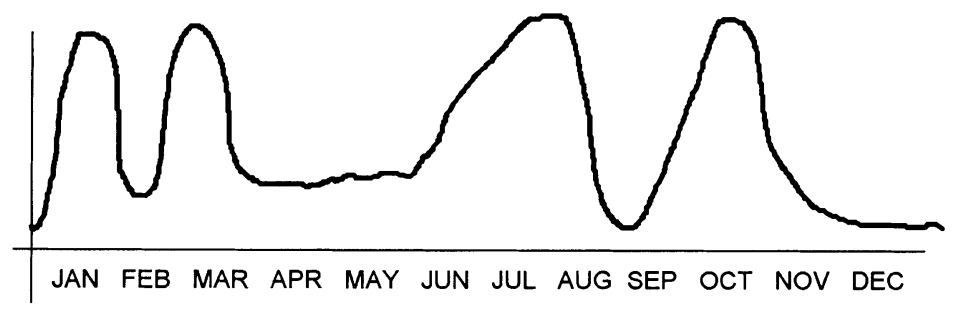

Figure 2. Peak work periods within the German school year

This work, e.g. writing reports, statistics, time-table production, students' matriculations and letters of acceptance normally has to be executed at very short notice. That is why teachers have to help the employees in the office.

\section{Student oriented form data}

A college of higher education normally includes several school types, each with its own curricula. For example, the Kaufmännische Schulen in Ahaus offer the following types of school:

1. Basic vocational school (commercial college)

2. Advanced vocational school (advanced commercial college)

3. Advanced vocational school with A-level qualification

4. Specialised high school (full time and part time)

5. Specialised school of economy, economy informatics

6. Vocational schools with classes for 10 different vocations.

Each type of school has its own report regulations. These must be closely adhered to because the school reports give the students particular qualifications. Just what qualifications they receive depends on their previous education as well as the average mark which they have achieved in their course of training. Due to the student oriented form data more than 140 form regulations must be obeyed at the Kaufmaennische Schulen Ahaus.

\subsection{Consequences for hardware and software}

\section{Decentralization}

The unstructured workload which has to be carried out in a few days makes a multi user system necessary. In the Kaufmaennische Schulen Ahaus we employ a UNIX-system to which 9 terminals, 3 printers and a card-reader for the marking cards are connected.

In order to enable decentralized input of data, the software has been designed so that depending on the application only reading, or writing and reading access to data is permissible. Furthermore safety measures had to be taken to ensure that access is only allowed to those users who are entitled to it. School office personnel has, for example, no access to school report 
data. On the other hand, the teachers responsible for writing reports have no writing access to time-table data.

The problem of having a large data input to be covered in a very short period, while minimizing individual effort is most clearly apparent in report writing. School reports are normally issued at the end of January as well as at the end of the school year in July. At the Kaufmaennische Schulen the marks of 2,000 students in an average of 12 subjects have to be gathered by about 70 teachers within three or four days. The input of marks into the mark files occurs at a time when the teachers already face an increased workload caused by their involvement in final examinations. That is why we had to develop a system for collecting marks that minimizes the workload. The solution is that the teachers mark the specially prepared computer-cards. The cards, which are issued at certain intervals, are fed into the computer in the morning breaks. The teachers all receive their own check-lists. If there are any errors, the teacher marks his correction on the list and gives them to the work-team responsible for report writing. One member of this team corrects the report file. This procedure has a number of decisive advantages over the collection of marks at a terminal:

- the teacher can collect his marks at a convenient time.

- the responsibility for collecting marks lies with the individual teacher.

- collecting marks is fully decentralized; in this way the time required for each individual is minimized.

- instruction in the marking procedure is clearly simpler than instruction of the teacher into operating the mark collecting program.

- the necessity of having to install rights of access to over 70 teachers with corresponding entitlements no longer exists for the system administrator (normally a teacher of informatics).

\section{Control of form organization}

The difficulty of ensuring that each student receives the correct form corresponding to his own type of schooling is also illustrated in the example of report writing. Reports not only include marks, but also additional remarks consisting of particular qualifications. That is why each report must be exactly matched to the type of schooling of the individual student.

The days on which the reports are issued are already filled with examinations and conferences. In the generally hectic atmosphere at the end of the school year many teachers lack the concentration to be able to issue the correct reports. A wrongly issued report have far-reaching consequences. Indeed, one school was taken to court and sued for compensation because a teacher had inadvertently employed incorrect report forms. Unfortunately this can easily happen because the Minister of Education frequently alters the legal regulations which can also lead to slight yet decisive changes in the texts of the reports. For this reason a school administration program must be designed in such a way that the teacher is only responsible for supplying the marks. All other data relevant to the writing of reports must be supplied in files or tables. 
The school administration software must enable the report program to make alterations with minimal effort. This is because schools have no money for regular program updates. The program system must be structured in such a way that instructed teachers can carry out the necessary alterations without any great difficulty. This is best achieved by saving the data necessary for controlling forms in special parameters and decision tables. This presupposes that the conditions are described in a formalized manner or, alternatively, are converted into reference numbers. Thus the type of schooling of each student is clearly marked by a schooling type number in the students data record. Each type of schooling has its own table of subjects. It is also clearly indicated whether the mark for each subject is relevant to the calculation of the student's average mark.

\begin{tabular}{|c|c|c|c|c|c|}
\hline $\begin{array}{l}\text { School type } \\
\text { number }\end{array}$ & 32301 & 32301 & 32301 & 32301 & 32301 \\
\hline type of report & $\begin{array}{l}\text { leaving } \\
\text { certificate }\end{array}$ & final report & final report & final report & $\begin{array}{l}\text { intermediate } \\
\text { report }\end{array}$ \\
\hline $\begin{array}{l}\text { previous } \\
\text { education }\end{array}$ & -- & D & E & $\mathrm{F}$ & -- \\
\hline average mark & -- & $<2.5$ & $<2.5$ & $<2.5$ & -- \\
\hline form number & 32301.1 & 32301.2 & 32301.3 & 32301.4 & 32301.0 \\
\hline
\end{tabular}

Figure 3. Structure of the decision table for writing reports

Parameters as well as the conditions which are important for writing reports are collected in decision tables as can be seen in figure 3 and are evaluated by the report program. The system administrator keeps the decision tables and produces the necessary form files. By this method of creating parameters one can ensure that the teachers are only involved in supplying marks on the computer cards.

\section{DIFFICULTIES OF IMPLEMENTING THE INTEGRATED DATA PROCESSING CONCEPT}

An integrated school administration application can only be successfully employed when it is matched by the internal organization of the school. Therefore a team of teachers must be formed that takes over the tasks of system administration. In compensation they receive a reduction in their weekly teaching load. If, however, other teachers cannot take on the extra lessons thus incurred, an integrated concept should be avoided..

The school administration applications which were developed predominantly according to the motto "teachers help teachers", 10 to 15 years ago, require updating. Further development in BASIC no longer seems to be a suitable solution. The new concept must be based on a database system which can be administered by SQL. The necessary procedural components are to be written in COBOL or $\mathrm{C}++$. It is of the greatest importance that the school administration 
application runs under the following operating systems: UNIX, NOVELL and WINDOWS. Only this can guarantee that the individual features of the schools are taken into consideration.

When developing new software, the ministry will only develop the software it needs for its own purposes because of the law concerning its budget. The local authorities will also only be interested in the software relevant to themselves. The schools for their part will write the programs they need themselves. However, if all three parties in the field of school administration agree on one data framework and one filing system, there is indeed a chance that the separate developments will lead to an all-embracing program system. 